\title{
A Forma Social da Comunicação no Contexto Soviético: Pertinência de Categorias da Economia Política da Informação, Comunicação e Cultura para o Estudo da Comunicação na URSS
}

The social form of communication in the Soviet context: Relevance of Political Economy of Information, Culture and Communication Categories for the Study of Communication in the USSR

\author{
Manoel Dourado Bastos* \\ Tatiana laquinto Ywatsugu ** \\ Willian Casagrande Fusaro ***
}

\section{RESUMO}

O presente artigo investiga os fundamentos lógicos da forma social da comunicação no âmbito soviético, reconhecendo a pertinência das categorias da Economia Política da Informação, Comunicação e Cultura para o estudo da comunicação na URSS. Primeiramente foram avaliadas duas interpretações dialéticas da experiência soviética (Arthur, 2016 e Kurz, 1999), a fim de entendê-la como parte de um sistema mundial produtor de mercadorias. Observada a permanência peculiar da forma do capital como substância das relações sociais no contexto soviético, avalia-se em que termos a derivação da forma social da comunicação, sua materialidade e funções (Bolaño, 2000) são pertinentes para uma interpretação da comunicação na URSS.

Palavras-chave: Forma Social da Comunicação; URSS; Função Publicidade;

\begin{abstract}
This article investigates the logical foundations of the social form of communication in the Soviet context, recognizing the relevance of the Political Economy of Information, Culture and Communication categories for the study of communication in the USSR. First, two dialectical interpretations of the Soviet experience were evaluated (Arthur, 2016 and Kurz, 1999), in order to understand it as part of a global commodity-producing system. Observing the peculiar permanence of the form of capital as a substance of social relations in the Soviet context, it is evaluated in what terms the derivation of the social form of communication, its materiality and functions (Bolaño, 2000) are relevant for an interpretation of communication in the USSR

Keywords: Social Form of Communication; USSR; Advertising
\end{abstract}

\footnotetext{
* Doutor em História pela Universidade Estadual Paulista Júlio de Mesquita Filho (Unesp), campus de Assis. Professor Adjunto do Departamento de Comunicação da Universidade Estadual de Londrina (UEL). Endereço: Rodovia Celso Garcia Cid, PR 445 Km 380, Campus Universitário, CEP 86.057-970, Londrina, PR. Telefone: (43) 3371-4328. E-mail:manoel.bastos@gmail.com

** Mestre em Comunicação pela Universidade Estadual de Londrina. Endereço: Rodovia Celso Garcia Cid, PR 445 Km 380, Campus Universitário, CEP 86.057-970, Londrina, PR. Telefone: (43) 3371-4328. E-mail: tati.iaquinto@gmail.com

*** Mestre em Comunicação pela Universidade Estadual de Londrina. Endereço: Rodovia Celso Garcia Cid, PR 445 Km 380, Campus Universitário, CEP 86.057-970, Londrina, PR. Telefone: (43) 3371-4328. Email:williancfusaro@gmail.com
} 
Função Propaganda; Informação para a Dinâmica de Trabalho.
Function; Propaganda Function; Information for Labour Dynamics.

\section{INTRODUÇÃO}

É relativamente surpreendente aos estudiosos da história da comunicação que a experiência televisiva soviética tenha começado precocemente, já no início da década de 1930, acompanhando a par e passo as demais tentativas de produção de um aparelho televisor funcional na Europa e Estados Unidos. É fato que o acento russo dessa experiência é mais ou menos inevitável, dada a importância do trabalho pioneiro de Boris Rosin em São Petersburgo no início da primeira década do século XX para o desenvolvimento do tubo de raio catódico visando a recepção de imagens, projeto que viajou junto com Vladimir Zworykin da Rússia para os EUA e gerou a proeminência da RCA na escalada rumo ao televisor funcional. Mas, vista assim, a participação russa na origem da TV fica restrita à lista de curiosidades e eventos episódicos. Menos estudado é justamente o fato de que na URSS em particular e no bloco comunista como um todo o desenvolvimento dos sistemas de comunicação foi simétrico àquele característico da lógica do capitalismo monopolista e da Indústria Cultural desde seus inícios. Desencorajados pelo caráter socialista a pensarem essa experiência em termo da consolidação de um mercado nacional, os estudos costumam se fixar num debate sobre controle, censura e as condições políticas autoritárias da TV na URSS, adotando princípios teóricos no mais das vezes liberais ao apontar para uma espécie de esfera pública falhada, o declínio como a característica marcante da mudança estrutural observada por Habermas no contexto ocidental, mas em outros termos.

Kristin Roth-Ey e Larissa Zakharova (2015), na apresentação do dossiê dedicado às Comunicações e Mídia na URSS e Europa Oriental na Cahiers du Monde Russe, apontam para o uso analiticamente descuidado da categoria habermasiana de "esfera pública" para o contexto dos países do socialismo realmente existente. Entendida equivocadamente como uma categoria analítica atemporal, para as autoras a sua aplicação sem qualquer ponderação histórica perde justamente a substância temporal que Habermas nela encontrou, mesmo que possamos afirmar que ele estivesse embebido de certo pendor para os tipos ideais weberianos. Extrapolando as determinaç̃oes históricas e geográficas para os tipos habermasianos de esfera pública, os estudiosos que se utilizam da categoria para avaliar a experiência cultural e comunicacional dos países do socialismo realmente existente acabam por torná-la um construto analítico estéril, mostrando-se muito mais uma exigência política deslocada do que um esforço de interpretação crítica.

Ambas estudiosas destacadas da comunicação e da "cultura de massas" na URSS", Roth-Ey e Zakharova (2015) não recusam a pertinência da categoria de "esfera pública", mas sugerem alguns pontos históricos a serem levados em conta e que são observáveis nos artigos publicados no dossiê. Primeiro, segundo elas, trata-se de compreender que, no contexto soviético, a dicotomia opositora entre o privado

\footnotetext{
${ }^{1}$ Roth-Ey (2011) publicou um livro decisivo sobre o papel midiático na construção de uma "cultura soviética" e sua derrota na "Guerra Fria cultural". Zakharova (2011), que nos deixou recentemente ainda muito jovem, publicou um livro sobre a moda na URSS na época do degelo. Ambas publicaram diversos artigos decisivos sobre as comunicações na URSS (ROTH-EY, 2004, 2007 e 2010) e (ZAKHAROVA, 2013, 2015a, 2015b e 2015c), textos relevantes para a investigação de que esse artigo é um primeiro esboço de exposição.
} 
(destituído de qualquer autonomia, reconhecida como resquício burguês) e o público (carente da pretensa liberdade democrática capitalista) apareceu segundo as categorias complementares do pessoal e do comunal (ou comum) - o que as leva a sugerirem uma passagem da sociologia das esferas públicas a uma gramática dos lugares comuns. A partir disso, desdobram outro aspecto, que diz respeito ao reconhecimento da diferença entre culturas oficiais e não-oficiais e o grau de autenticidade ou falsidade delas. Segundo as autoras, a partir desses aspectos o estudo empírico da história da URSS levou em geral a duas definições, uma restrita e outra ampla, de esfera pública para o contexto soviético. A restrita define esfera pública ligando-a à produção de uma ortodoxa opinião pública a partir da ação dos ativistas e militantes do regime; a ampla diz respeito a uma variedade de práticas e a espaços formais e informais, incluindo a resistência e dissidência.

Com esses aspectos postos, Roth-Ey e Zakharova buscam uma conciliação entre eles e a concepção habermasiana de declínio da esfera pública, própria ao século XX, sob a condição de aclamação plebiscitária, dominada pela opinião na ausência do debate público. Assim, chegam a uma distinção de três esferas públicas no âmbito do socialismo realmente existente: 1 ) a esfera pública da aclamação plebiscitária, de caráter oficial; 2) uma esfera pública semicontrolada, passível de manobras em suas próprias estruturas, com suas críticas camufladas e referências cifradas e que, segundo as autoras, efetivamente viabilizou a longevidade do regime; e 3) bolsões de oposição ao Estado, críticos e ilegais. Perceba-se que, mesmo em negativo, o Estado é o fundamento peculiar da esfera pública no âmbito do socialismo realmente existente. Ele é entendido exclusivamente em seu papel de controle e propaganda. A explicação a isso, tautologicamente, volta a uma fundamentação mais ou menos "totalitária" do "regime", princípio político que passa a ser questionado em seus resultados (ou seja, o fechamento e controle não são suficientes para eliminar o funcionamento complexo, multifacetado e amplo da esfera pública e do sistema midiático).

O presente artigo apresenta, sob a forma de um exercício lógico, uma investigação que vai além da classificação da superfície da práxis comunicacional do socialismo realmente existente. Para tanto, reconhece a Economia Política da Informação, Comunicação e Cultura (EPICC) como o âmbito teórico capaz de buscar os fundamentos dessa práxis. Nesse sentido, adotaremos a abordagem que investiga a comunicação como uma forma social, presente na obra de César Bolaño (2000) Indústria cultural: informação e capitalismo. Aproveitando o denso debate sobre a derivação do Estado que se desdobrou principalmente na República Federal da Alemanha em $1970^{2}$, com ecos posteriores na Grã-Bretanha, Bolaño (2015) reconhece o "método da derivação das formas" como um aporte decisivo para a EPICC. Assim, antes de se perguntar sobre o funcionamento da mercadoria própria à comunicação, trata-se de entender a comunicação como uma forma social peculiar ao capitalismo. Ao visar um estudo da comunicação no âmbito soviético, o estudioso da EPICC que trilha pelo caminho do "método da derivação das formas" se coloca diante de uma dúvida: uma categoria destinada ao estudo da comunicação peculiar ao capitalismo é pertinente no estudo da experiência da comunicação própria ao sistema que pretendeu abolir a dinâmica do capital?

Para dirimir a dúvida, num primeiro momento determinaremos se e como a categoria dialética da "forma social" é um construto teórico adequado para a interpretação da

\footnotetext{
${ }^{2} \mathrm{O}$ debate sobre a derivação do Estado está disponível em espanhol em BONNET e PIVA, 2017.
} 
experiência social iniciada em 1917. Nesse sentido, recorreremos inicialmente a análises da URSS ancoradas nessa categoria dialética. O primeiro texto se trata de um pequeno artigo de Christopher J. Arthur (2016), publicado em meio a suas investigações sobre as relações entre aquilo que ele nomeia de "nova dialética" e $O$ Capital, de Marx (2017). A segunda obra é o livro clássico de Robert Kurz (1999), O Colapso da modernização, que investiga a derrocada do socialismo realmente existente como expressão da crise do capitalismo.

Em seguida, resolvida a pertinência da categoria de forma social para a interpretação da experiência soviética, passaremos a lidar especificamente com a comunicação como forma social, amalgamando a derivação e particularizações promovidas por Bolaño (2000) com as afirmações de Arthur e Kurz sobre a URSS. Assim, reconheceremos os fundamentos da práxis comunicacional tal qual foi exposta em seus aspectos mais aparentes por Roth-Ey e Zakharova.

\section{MERCADO, ESTADO E O CONTEXTO SOVIÉTICO}

Arthur busca uma interpretação da União Soviética e seu ocaso a partir das categorias de sua "dialética sistemática", desenvolvidas previamente por ele como uma abordagem peculiar da teoria do valor de Marx. No artigo sobre a URSS, Arthur (2016) inicia seu argumento com a questão das categorias dialéticas de forma, conteúdo e matéria. Nos termos de Arthur (2016, p. 226), enquanto “(...) a matéria é indiferente à forma externamente imposta a ela", o conteúdo é exatamente adequado à forma. Sinteticamente, conteúdo é a matéria que passa à exata adequação formal.

A partir destas três categorias primordiais da dialética, Arthur produz uma interpretação do capitalismo.

\footnotetext{
O capital é em sua forma um valor que se autovaloriza; mas, para os propósitos desta discussão, o processo de valorização pode ser tomado como incorporado no processo material de produção, e este último tratado como um conteúdo que assume a forma da autoprodução de capital por meio da apropriação de mais-valia. (ARTHUR, 2016, p. 226)
}

Acompanhando a observação histórica de Marx na passagem da cooperação simples à grande indústria, ou seja, da subsunção formal à subsunção real do trabalho ao capital, Arthur aponta justamente a passagem da externalidade da unidade entre forma e matéria até a exata adequação e imanência entre forma e conteúdo. "Em suma, o capital como forma (valor que se autovaloriza) agora produz do interior de si mesmo um conteúdo adequado a ele: o sistema fabril. A chave é a subordinação dos trabalhadores com a reorganização da divisão do trabalho e a construção de uma hierarquia de controle" (ARTHUR, 2016, p. 228). Em caso de conflito entre forma e conteúdo, está dada a necessidade objetiva para a superação do sistema.

Quando passa para a avaliação do "modelo soviético", um daqueles "sistemas pósrevolucionários que alegavam ter superado o capitalismo", Arthur afirma imediatamente que, desde o prisma da "forma social", "o capitalismo foi destruído na URSS" (ARTHUR, 2016, p. 233). Contudo, segundo Arthur, o caráter material do capital, ou seja, o sistema fabril, permaneceu. Com este, permaneceram a divisão hierárquica do trabalho e a configuração técnica, desprovidas da regulação econômica da autovalorização do valor, i.e., sua forma. Estamos diante de uma inadequação entre forma e conteúdo. 
O problema surge precisamente porque a materialização do capital foi liberada da forma de controle do capital, mas sem que outro sistema orgânico de metabolismo social se enraizasse e transformasse mais ou menos rápida e radicalmente as bases materiais da economia. Não sendo nem capitalismo nem socialismo, à URSS faltava coerência orgânica (ARTHUR, 2016, p. 234).

Arthur passa a acompanhar alguns aspectos dessa inadequação, pautados pela ineficiência do planejamento central, como trabalho intensivo, omissão de recursos, descompasso na oferta de mercadorias, produtos com defeitos, escassez de recursos humanos e tecnológicos etc. Sem a dinâmica da lógica do capital, argumenta Arthur, as fábricas soviéticas viveram uma situação de baixa produtividade e exploração ineficiente, pautada pelo controle do aparato burocrático e seus gestores privilegiados por premiações.

Nesse ponto, Arthur (2016, pp. 238-9) faz duas menções importantes aos âmbitos da informação e da comunicação. A primeira diz respeito à ausência de uma “institucionalização mutuamente informativa das relações produtor/consumidor", que seria fundamental na produção voltada para necessidades, em substituição à transmissão (fetichista, vale acrescentar), por meio da lei do valor, do tempo de trabalho socialmente necessário para a produção dos itens e do reforço mútuo entre fluxos de capital e inovação tecnológica. Na URSS, argumenta Arthur, a propalada planificação da produção visando as necessidades dava lugar à externalidade das metas das fábricas, desligadas das necessidades, dos recursos e das capacidades reais de produção. Por sua vez, os planos quinquenais, afirma Arthur, eram fundamentados em informações corrompidas pelas "distorções políticas do sistema".

Assim, Arthur afirma que os surtos de expansão dos fatores básicos de produção eram seguidos por paralisias crônicas, o que deveria ser entendido como resultante da ausência de qualquer lei econômica no âmbito soviético, o que nos leva à segunda menção aos âmbitos da informação e da comunicação. ${ }^{3}$ Tais surtos eram consequência da priorização na alocação de materiais, máquinas e trabalhadores, processo que funcionou na economia de guerra e que, com a presença do imperialismo e a dinâmica da Guerra Fria, gerou a concentração no setor armamentista e viabilizou a produção e lançamento do Sputnik em 1957. A impressionante experiência soviética na corrida espacial, com o lançamento de diversos satélites e espaçonaves entre os anos 1950 e 1960, gerou também, em 1971,

\footnotetext{
3 Poderíamos contrastar o argumento de Arthur, escorado em economistas importantes como Hillel Ticktin, Bob Arnot e Frank Furedi, com o belo trabalho de Robert C. Allen (2003), que promove uma vigorosa reinterpretação da revolução industrial soviética, apontando-a como o mais impressionante desenvolvimento econômico do século XX. Contudo, estaríamos em terrenos conceituais muito distintos. De qualquer modo, a menção ao trabalho de Allen serve de alerta para o apressamento nas passagens de Arthur da abstração das categorias dialéticas para a empiria da contingência. Seria preciso acompanhar em períodos mais longos a assertiva lógica de Arthur sobre a ausência de lei econômica. Adiante, a partir da interpretação de Robert Kurz, daremos uma chave de interpretação nesse sentido, invertendo aspectos do argumento de Arthur. Em que pese o argumento de Allen ser positivo com relação ao desenvolvimento econômico soviético, ele de certo modo cacifa o raciocínio de Robert Kurz sobre o caráter de "modernização retardatária" de Kurz, que veremos a seguir.
} 
uma organização que coordena um sistema de satélites voltados à comunicação interligando um conjunto de oito países do bloco socialista, a Intersputnik. ${ }^{4}$

Também partindo de premissas da teoria marxiana do valor, Robert Kurz (1999) desenvolve sobre os problemas tratados por Arthur argumentos diferentes. Entendemos que o encaminhamento diverso de Kurz dá mais estofo ao argumento de Arthur e viabiliza uma compreensão adequada da permanência peculiar da forma social da comunicação no contexto soviético. Assim, ao contrário de Arthur, Kurz compreende a experiência do socialismo realmente existente como parte constitutiva de um sistema mundial produtor de mercadorias. Significa dizer, nos termos de Kurz, que:

Desde o princípio, o socialismo real não podia suprimir a sociedade capitalista da modernidade; ele próprio é parte do sistema produtor burguês de mercadorias e não substitui essa forma social histórica por outra, mas sim representa somente outra fase de desenvolvimento dentro da mesma formação de época (KURZ, 1999, p. 25).

Para Kurz (1999, p. 21), que foca sua compreensão do sistema mundial produtor de mercadorias, o cerne está na "forma específica do trabalho e o conceito de trabalho correspondente", ou seja, o trabalho abstrato. Assim, o "mercado planejado" soviético mantém as categorias do capitalismo (como salário, preço e lucro), levando o trabalho abstrato às últimas consequências na dinâmica de um regime de transição para a modernidade.

Não é o caso aqui de entrar numa discussão a respeito do teor depreciativo das avaliações de Kurz sobre o socialismo real. O tom polêmico das assertivas, certo ou errado, importa pouco para o quadro que estamos apontando aqui. Mais relevantes são os comentários em torno da permanência formal da (re)produção da mercadoria no socialismo realmente existente, frustrando os esforços de sua supressão a partir da instrumentalização do Estado (que Kurz avalia, pelo contrário, como o motor mesmo da modernização retardatária que, ao colapsar, anuncia a crise do sistema como um todo). Interessa para Kurz, especificamente, compreender como a pretensa sobreposição da coação das leis da concorrência pelo poder estatal na verdade significava uma manutenção lógica, ainda que aparentemente imperfeita, da forma da mercadoria.

Em vez de observar como antípodas, Kurz avalia o que chama de estatismo e monetarismo como complementares, em alternância. $O$ estatismo do socialismo realmente existente é entendido por Kurz como sua forma de atuação no moderno sistema mundial produtor de mercadorias. Para Kurz, assim como havia ocorrido em outros momentos da história do capitalismo, o estatismo próprio à economia de guerra do socialismo realmente existente visava

(...) impor a subordinação das necessidades, finalidades e intenções humanas à riqueza nacional abstrata de um sistema produtor de mercadorias e ao seu crescimento e também ao direcionamento sistemático dos homens [sic] a esta finalidade "sem sentido" (KURZ, 1999, p. 65).

\footnotetext{
4 John D.H. Downing (1985a e 1985b), importante estudioso da "Mídia Radical”, publicou na década de 1980 dois relevantes artigos sobre o sistema Intersputnik de satélites e a televisão soviética. É uma importante referência para a dinâmica dos sistemas soviéticos de comunicação que serão observados num nível mais abstrato e formal aqui neste artigo.
} 
Restavam congeladas as relações complementares entre estatismo e monetarismo, que, contudo, permanecia no fundamento formal da experiência soviética. Kurz encontra aí mais um elemento para corroborar sua tese do socialismo realmente existente como parte integrante do sistema mundial produtor de mercadorias ao afirmar que, em vez de asseverar a abolição da circulação na URSS, trata-se de reconhecê-la num funcionamento distinto, numa tentativa malsucedida de seu planejamento. "A Revolução de Outubro fez surgir um moderno sistema produtor de mercadorias, sem permitir que este seguisse seus próprios mecanismos funcionais; a concorrência entre os participantes do mercado foi impossibilitada e substituída pelo comando estatal" (KURZ, 1999, p. 76).

Ou seja, o estatismo não só não abole a circulação e a concorrência, mas as realiza em termos negativos e por outros meios. Segundo Kurz, há uma razão lógica para isso. Dialeticamente, o desenvolvimento econômico da URSS só era possível pela adoção do estatismo e a consequente paralisação da concorrência. Isso porque a possibilidade de enfrentar a concorrência externa dos países ocidentais desenvolvidos impunha à URSS o congelamento e controle da concorrência interna, a fim de evitar sua absorção dependente ou marginalização da economia nacional. Assim, o pretenso "mercado planejado" desviava massas de mais-valia para setores das indústrias básicas e de infraestrutura anulando o "princípio funcional da própria produção de mais-valia" (KURZ, 1999, p. 77).

Entendemos que a forja da manifestação peculiar da forma social da comunicação no contexto soviético parte daqui. Segundo Kurz, o controle estatal sobre o desvio de massas de mais-valia, cortada a concorrência interna, somente poderia incentivar o aumento de produtividade por meio de "campanhas de propaganda morais". Veremos adiante que esta é a alma da confusão entre as funções da forma social da comunicação. Para Kurz, está na relação contraditória entre o uso intensivo de força e trabalho, a produtividade rebaixada e o empacar do desenvolvimento das forças produtivas a explicação para o ocaso soviético - ou seja, algo inteiramente afeito ao âmbito da teoria marxiana do valor.

Assim como observado por Arthur, Kurz acompanha as ineficiências do sistema fabril soviético. Ao contrário de Arthur, contudo, Kurz entende essas ineficiências justamente pela permanência fundamental da dinâmica do valor num sistema que visava substituir as leis da coação econômica e da concorrência pelo "mercado planejado" estatal. A relação irracional de reprodução do capital, baseada na oposição recíproca constante entre produtor (interessado no valor de troca) e consumidor (interessado no valor de uso), é regulada, desde um ponto de vista econômico, pela concorrência. Ela garante, no âmbito do sistema mundial produtor de mercadorias, certa dose de atenção no âmbito da produção ao valor de uso tanto quanto impele ao desenvolvimento das forças produtivas, nesses termos necessariamente levando em conta, de algum modo, as "necessidades".

O contexto soviético, ao ser determinado não pela concorrência, mas pela coação estatal, gerou resultados lamentáveis de controle burocrático. Vale ressaltar que, além da possibilidade de enganação do controle burocrático pelos trabalhadores e empresas, a falta de interesse nos valores de uso se dá pelo fato da própria burocracia privilegiar, dadas as leis do valor, as unidades fabris que produzem mais valor, com o mínimo de produtividade e o máximo de desperdício - o que ironicamente Kurz chama de "competição em preguiça" e "otimização contraprodutiva" (KURZ, 1999, p. 93). Assim, a extensa economia de escassez e o estatismo do socialismo realmente existente geraram, nos termos de Kurz, uma “concorrência negativa” (KURZ, 1999, p. 111). Como a abolição da concorrência não 
eliminou a circulação, sua contradição estava justamente em atender, de um lado, aos desígnios da produção de mais-valia, o que implicava numa baixa importância do crescimento da produtividade, e, de outro, evitar a baixa qualidade do produto, tentando privilegiar o valor de uso. A externalidade da solução dessa contradição está no centro do debate sobre a forma social da comunicação no contexto soviético, como veremos.

Enfim, as categorias dialéticas de forma, conteúdo e matéria se mostram pertinentes para uma interpretação da experiência soviética. Observando criticamente os trabalhos de Arthur (2016) e Kurz (1999) podemos reconhecer que o "socialismo realmente existente" da URSS se constituiu como uma expressão peculiar da forma social do sistema mundial produtor de mercadorias. Longe de abolir o capital, seu fundamento ainda estava atrelado às leis do valor. Trata-se agora de avaliar, a partir dos pressupostos aqui apresentados, em que termos a experiência soviética forjou uma peculiar forma social da comunicação.

\section{PECULIARIDADES DA FORMA SOCIAL DA COMUNICAÇÃO NO CONTEXTO SOVIÉTICO}

Dirimidas as dúvidas sobre a pertinência da categoria dialética de "forma social" para o estudo do socialismo realmente existente da URSS, passaremos a avaliar a comunicação no contexto soviético. Se o fundamento da dinâmica social na URSS estava numa manifestação peculiar da forma elementar da mercadoria e do trabalho abstrato, baseada no congelamento do estatismo visando a modernização retardatária, parece-nos pertinente avaliar a forma social da comunicação pensando nessas condições truncadas. Para isso, levando em conta que se trata de um exercício lógico $^{5}$, a pergunta que recai sobre a categoria de forma social da comunicação é como ela se organiza segundo esses aspectos diferenciados da experiência soviética. Para responder a isso, vamos acompanhar alguns dos aspectos gerais, tal qual encontramos na exposição de Bolaño (2000), reposicionando seus fundamentos lógicos de acordo com as peculiaridades da experiência soviética. Trata-se, enfim, de um exercício de particularização análogo ao desdobrado pelo próprio Bolaño para chegar na possibilidade lógica da Indústria Cultural.

No nível mais alto de abstração, aquele relativo à forma elementar da mercadoria (ou o momento da circulação simples), temos possuidores de mercadorias trocando informações objetivas, sem mediações, visando o ato da troca. Ou seja, trata-se de um processo cooperativo de interpretação (uma ação comunicativa, nos termos de Habermas), visando a metamorfose das mercadorias. A substância da informação está nas condições de torná-la pública. Como limite imanente à informação já nesse âmbito, a manipulação se mostra como uma possibilidade lógica que, contudo, ainda não se concretiza, visto que o fundamento do processo é a igualdade formal entre os participantes. Outro limite imanente é a possibilidade lógica da unidirecionalização e

\footnotetext{
${ }^{5}$ De fato, o exercício lógico aqui apresentado está balizado por duas pesquisas desenvolvidas ao longo do Mestrado em Comunicação na Universidade Estadual de Londrina. Uma delas desenvolve uma análise do estúdio soviético de animação, o Soyuzmultfilm, focando principalmente a era do degelo (YWATSUGU, 2020). A outra faz uma análise de um conjunto de pôsteres produzidos durante o período de Guerras Civis, como instrumento de agitação e propaganda (FUSARO, 2020). Nas duas pesquisas, a observação da forma social da comunicação se fez por meio da categoria de esfera pública proletária desenvolvida por Kluge e Negt (2016).
} 
monopolização da informação, mas como nesse momento formal o Estado ainda não é uma instância pertinente isso ainda não se concretiza.

Ao sairmos do reino da igualdade da circulação simples rumo ao espaço obscuro da produção, a figura dos possuidores de mercadorias muda de característica e o possuidor da força de trabalho se apresenta como trabalhador, assim como o possuidor de dinheiro e meios de produção como capitalista. Neste âmbito, a informação continua não mediada, direta e objetiva, mas agora hierarquizada e burocratizada. A comunicação como troca de informação entre iguais, sua aparência, se interverte na troca de informação de classes, seu fundamento. Toda a particularização da forma social da comunicação, do âmbito mais abstrato rumo ao mais concreto, lida com essa contradição substancial.

A apresentação de César Bolaño (2000), partindo desse pressuposto e atentando para o desenvolvimento histórico dos grandes sistemas de comunicação desde o século XIX, passando pelo debate da esfera pública burguesa e desaguando no aparecimento da Indústria Cultural, particulariza essa contradição formal da comunicação acompanhando a exposição marxiana da passagem da cooperação simples à grande indústria. Essa passagem se origina na apropriação pelos capitalistas do conhecimento gerado na produção, desde aqueles desenvolvidos pelos mestres artesãos até aqueles consolidados pelos trabalhadores fabris, o que Bolaño (2000) chama de acumulação primitiva de conhecimento.

No sistema fabril, a produção implica em algum nível de circulação das informações entre os próprios trabalhadores, conhecimento que, ao ser entendido como insumo e apropriado pelo capitalista, torna-se potencialmente uma mercadoria. Assim, ela se apresenta como um elemento chave na dinâmica concorrencial. A expansão de ação da grande empresa capitalista vai exigir sistemas de armazenamento, processamento e difusão da informação cada vez mais robustos, a fim de oferecer as condições e estruturas administrativas as mais adequadas possíveis dado o crescimento da escala. De outra parte, ela vai demandar a consolidação de um corpo técnico e burocrático também capaz de gerenciar, a partir do uso da informação direta e hierarquizada, os processos de trabalho na grande empresa capitalista em escala expandida. Ou seja, de um lado, aquela informação relacionada ao processo de trabalho e, de outro, aquela relacionada à concorrência capitalista. Os grandes sistemas de comunicação gerados para comportar o crescimento de escala (telégrafo, telefonia etc.) lidam com as contradições entre esses dois aspectos.

Podemos adentrar já a partir daqui num primeiro nível da abordagem da forma social da comunicação no âmbito do socialismo realmente existente. Avaliamos que a contradição da informação própria a esse momento (informação relacionada à concorrência e informação relacionada ao processo de trabalho), relacionada ao desenvolvimento dos grandes sistemas de comunicação, se apresentou de maneira diferenciada no contexto soviético. A se tirar pela argumentação de Arthur (2016), a adoção dos grandes sistemas de comunicação deveria ser vista exclusivamente pelo prisma da matéria que, neste âmbito específico, era o análogo ao sistema fabril. Contudo, observaremos adiante que o desenvolvimento das funções específicas da forma comunicação geraram outras contradições.

Vimos acima que Arthur aponta para a ausência de uma "institucionalização mutuamente informativa das relações produtor/consumidor" e para a presença das informações corrompidas pelas "distorções políticas do sistema", disfuncionalidades que seriam geradas pelo vácuo da forma social do capital. Nesses termos, aquilo que, segundo a EPICC, resultante da contradição entre a informação mercadoria 
caraterística da dinâmica da concorrência e o gerenciamento e administração dos processos de trabalho por meio da informação, desaguando no desenvolvimento dos grandes sistemas de comunicação, se apresentaria no contexto soviético como um problema de ausência de organicidade formal. A partir da dialética sistemática de Arthur (2016) aplicada à URSS, a EPICC deveria entender a situação como uma ausência formal da comunicação, da incapacidade de concretização de uma nova forma e da permanência da matéria social dos grandes sistemas de comunicação, inviabilizados como conteúdo.

Contudo, a partir de uma análise dialética a partir da EPICC, podemos afirmar que as dimensões formais reconhecidas no nível mais abstrato de análise permanecem em substância na dinâmica soviética, expressas com sinais invertidos - ou seja, temos outra configuração da correlação entre a aparência da troca de informação (direta, objetiva e não mediada) entre iguais e de sua interversão no fundamento da informação de classe (hierarquizada) do terreno obscuro da produção. O que visualizamos na dinâmica informacional gerada pela planificação falhada e sua substituição pelas metas e planos burocráticos é uma expressão, fetichista a seu modo, das leis do valor, cuja aparência é a administração e gerenciamento por meio da forma social do Estado. ${ }^{6}$ As possibilidades formais de manipulação, unidirecionalização e monopolização da informação, presentes já no âmbito da comunicação entre iguais, se sobrepõem como aparência na burocratização do sistema fabril. Não se trata de um vácuo formal, gerando disfuncionalidades materiais, mas uma concretização em outros termos das contradições presentes na própria forma social da comunicação.

Assim, ao entendermos, com Kurz (1999), a dinâmica econômica da URSS como um processo de modernização retardatária, podemos visualizar em outros termos a corrida soviética para alcançar as condições dos grandes sistemas de comunicação disparadas pela acumulação primitiva de conhecimento e as resultantes da mercadoria-informação e as estruturas gerenciais do processo de trabalho. Impedidos os caminhos da concorrência interna entre empresas, foram a burocracia e a fiscalização estatais que buscaram fazer suas vezes. A ausência da concorrência interna, por um lado, ao visar uma alta concentração de mais valia para o enfrentamento da concorrência externa, privilegiou a exploração extensiva de trabalho. Por outro lado, fez com que a qualidade dos produtos fosse colocada em segundo plano, num desinteresse pelo valor de uso. Em termos práticos próprios à lógica social da informação, abolida a concorrência como aparência capitalista, mas mantida a dinâmica do capital, a informação assume primordialmente aquela funcionalidade decisiva própria ao processo de trabalho.

Kurz afirma que a mera fiscalização se mostrou incapaz de substituir os pesos e contrapesos das "leis coercitivas da concorrência" (MARX, 2017, p. 393). A partir disso, Kurz (1999, p. 89) aponta que se gerou no âmbito soviético um rol repetido de campanhas que premiavam tanto as unidades fabris que produzissem mais valor (ou

\footnotetext{
${ }^{6}$ Há uma divergência teórica entre Kurz e Bolaño que merece nossa atenção. Enquanto Bolaño parte categorialmente da contradição entre a circulação simples e sua relação entre iguais com o terreno oculto da produção e sua relação de classes, Kurz desdenha a dimensão de classes e produz aquilo que chama de uma "crítica do marxismo operário", privilegiando em suas análises a crítica do valor e do trabalho abstrato. À revelia dessa divergência, parece-nos possível uma aproximação entre os dois, entendendo que a abordagem dialética da forma social da comunicação pode levar em consideração o caráter fetichista já no momento da circulação simples. Para isso, podemos mencionar o artigo de Bastos (2018).
} 
seja, exploração extensiva de trabalho, baixa produtividade e desperdício de material) quanto os produtores de mercadorias que se comportassem levando em conta os valores de uso, processo que ele chama de "subjetivação das leis coercitivas da concorrência". Isso vai nos colocar no terreno mais específico das funções próprias ao desenvolvimento dos sistemas de comunicação de massas, resultantes da autonomização da mercadoria informação.

O processo de massificação que se desenrola progressivamente desde o século XIX deve ser entendido tanto pelo prisma do uso intensivo em escala crescente de força de trabalho no sistema mundial produtor de mercadorias quanto do mercado voltado para o consumo de mercadorias em expansão. Em meio a esse processo, finalmente a mercadoria informação se autonomiza. Nos termos de Bolaño (2000), a informação massificada é a aparência que encobre a essência da informação de classe. Esse processo de autonomização da mercadoria informação externaliza a contradição entre a informação voltada para o trabalho e a informação voltada para a concorrência. De um lado, a forma comunicação passa a manifestar a informação diretamente em seus aspectos ideológicos, exercendo a funcionalidade de propaganda; de outro, a forma comunicação passa a expressar a informação dos termos relativo à acumulação de capital (ademais, ideologicamente comprometida em constituir um modo de vida capitalista), assumindo a funcionalidade de publicidade (BOLAÑO, 2000, p. 53). A EPICC tal qual estudada por Bolaño (2000) dá atenção à particularização destas funcionalidades, entendidas em sua necessidade massificada no âmbito próprio da Indústria Cultural.

Destaque-se que, por sua vez, no âmbito soviético a informação relativa ao processo de trabalho para dentro das próprias unidades fabris é possivelmente a mais decisiva, levando-se em conta sua permanência no sistema mundial produtor de mercadorias. O que no âmbito do capitalismo monopolista aparece como uma contradição da informação de massas que encobre a informação de classe se converte em outra lógica quando se trata do socialismo realmente existente. Trata-se inicialmente de observar que, tanto ou mais do que a informação massificada, é a informação própria à organização fabril que precisa ser levada em consideração na particularização da forma social da comunicação, determinando de maneira diversa aspectos do desenvolvimento dos grandes sistemas de comunicação e de suas funções.

Aquelas contradições próprias à informação que, no âmbito do capitalismo monopolista, materializaram-se nos grandes sistemas de comunicação e externalizaram-se em funções (ou seja, a Indústria Cultural), no socialismo realmente existente levaram a outras relações. No que diz respeito à Indústria Cultural, é a dinâmica própria à metamorfose das mercadorias que determina a necessidade de uma informação cujo cerne estar em tornar-se pública. É daí que os grandes sistemas de comunicação vão se desenvolver até assumir a forma de Indústria Cultural e as funções aí operadas. No socialismo realmente existente, seguindo o fracionamento da concorrência voltada para o âmbito externo, a comunicação competiu com e emulou materialmente sua simétrica desenvolvida no capitalismo monopolista. Ainda que subsumida à interrupção da dinâmica da concorrência, imperativo a informação tornar-se pública se fez presente, determinada, por um lado, pela proeminência dos aspectos relativos à informação voltada às relações de trabalho e, por outro, pela permanência material dos sistemas de comunicação cuja substância era a lógica massiva.

Ou seja, ainda que, expurgada a concorrência do socialismo realmente existente, a publicidade enquanto particularização da forma social da comunicação parecesse, em princípio, não cumprir funcionalidade alguma no sistema, sua possibilidade lógica 
estava dada. De fato, na medida em que a acumulação de capital não foi eliminada, mas sendo operada em outros termos, podemos afirmar que a publicidade funciona naquilo que foi descrito como seu nexo ideológico, tendo por motor a consolidação de um modo de vida cujo centro é a figura do trabalhador, mas que pode ser representado segundo tipos análogos de heróis e afins. ${ }^{7}$ Num certo sentido, levando em consideração o vetor ideológico próprio ao estatismo como pretenso substituto das "leis coercitivas da concorrência", é possível dizer que a separação entre as funções propaganda e publicidade se torna mais nebulosa.

De qualquer modo, dada a burocratização da informação no sistema fabril como substituta falhada da lógica concorrencial e a função publicidade cumprindo de maneira peculiar seu papel como vetor da circulação numa truncada organização social do capital, a presença no âmbito do socialismo realmente existente dos grandes aparatos comunicativos (que servirão de conteúdo social de desenvolvimento da Indústria Cultural nos países capitalistas) não pode ser reduzida a mera permanência material sem forma social adequada. A existência de toda uma dinâmica comunicacional com o desenvolvimento de sistemas de impressos, rádio, cinema e televisão deve ser observada segundo a ideia de que a concretização de uma "cultura soviética" midiática responde aos imperativos formais da lógica do sistema produtor de mercadorias, avaliando criticamente as funções propaganda e publicidade tal qual seus fundamentos peculiares ao contexto soviético.

Na medida em que os estudos sobre comunicação e cultura na URSS privilegiam seu fundamento político, as abordagens tendem a dar bastante atenção à função propaganda, ignorando as condições de funcionamento e mesmo a mera existência da função publicidade. Mas, é justamente sua presença, em termos superficiais diferentes daqueles reconhecidos no âmbito do capitalismo monopolista, que coloca a possibilidade de existência de uma dimensão por assim dizer pública da comunicação no socialismo realmente existente. Com isso, saímos da mera classificação dos âmbitos oficiais, semioficiais e não-oficiais, pensados segundo termos políticos, e entendemos por que o Estado no contexto soviético não se resume a um controle censório e a uma difusão propagandista. A forma social da comunicação, em sua configuração soviética, também cumpria uma função própria à circulação, ainda que a concorrência estivesse interrompida.

Enfim, a informação, em sua configuração característica de elemento na modernização retardatária própria à dinâmica do socialismo realmente existente, não pôde dirimir a lacuna entre as necessidades e a produção, assumindo a função de fomentar aspectos da circulação de capital num contexto de interrupção da concorrência, principalmente privilegiando as unidades fabris que viabilizavam a produção de mais valor, diminuindo a atenção dos trabalhadores sobre o valor de

\footnotetext{
7 Sobre isso, podemos fazer referência à figura do trabalhador (ou seus substitutos prototípicos heroicos) em pôsteres produzidos no contexto das Guerras Civis, após a Revolução de Outubro. Ao mesmo tempo em que o contexto de Guerras Civis apresentava possibilidades comunicativas que visassem superar a sorte de problemas apresentados aqui em seus aspectos lógicos mais formais, havia já ali os fundamentos do que identificamos como a distorção da função publicidade para o contexto soviético como um todo. Em Fusaro (2020), há a análise de um conjunto de pôsteres em que é possível observar as argumentações presentes que visavam sintetizar a figura do trabalhador que, convocado para a luta em prol da revolução bolchevique, o faz por meio de sua atividade na fábrica. Ywatsugu (2020), se referindo a Kluge e Negt (2016), lembra que, contudo, a fábrica também era o espaço em que se erigia uma esfera pública proletária, em contraste com o ambiente civil de mercado no qual opera a esfera pública burguesa. A figura do trabalhador comportava assim as contradições entre a circulação de mercadorias num regime de planificação burocratizada e as aspirações políticas para sua superação.
} 
uso, o que se tornava a determinação decisiva para as funcionalidades da informação naquela configuração específica do sistema mundial produtor de mercadorias.

\section{CONSIDERAÇÕES FINAIS}

O presente artigo investigou os fundamentos lógicos da forma social da comunicação no âmbito do socialismo realmente existente, fundamentalmente a experiência soviética. Para isso, era necessário reconhecer a pertinência das categorias da Economia Política da Informação, Comunicação e Cultura para o estudo do desenvolvimento dos sistemas de comunicação na URSS. Tendo isso em vista, primeiramente foram avaliadas duas interpretações da experiência soviética pelo prisma das categorias dialéticas de forma, matéria e conteúdo (a de Arthur, 2016 e a de Kurz, 1999), a fim de entendê-la como parte de um sistema mundial produtor de mercadorias. Entendida a permanência da forma do capital como substância das relações sociais no contexto soviético, foi possível avaliar em que termos a derivação da forma social da comunicação e sua particularização em funções e materialidade (tal qual apresentado por Bolaño, 2000) eram pertinentes para uma interpretação da comunicação na URSS. A partir do prisma lógico aqui apresentado, entendemos que uma série de pesquisas empíricas podem ser desdobradas, fugindo das dicotomias liberais que invariavelmente recaem sobre os estudos que se dirigem ao âmbito soviético.

Artigo recebido em 31/01/2020 e aprovado em 24/04/2020.

\section{REFERÊNCIAS BIBLIOGRÁFICAS}

ALLEN, Robert C. Farm to Factory: A reinterpretation of the soviet industrial revolution. Princeton/NJ: Princeton University Press, 2003.

ARTHUR, Christopher J. Um relógio sem corda: epitáfio para a URSS. In: A nova dialética e "O Capital" de Marx. Tradução de Pedro C. Chadarevian. São Paulo: Edipro, 2016.

BASTOS, Manoel Dourado. O caráter fetichista da informação necessária no momento da circulação simples. Revista Eptic, Vol. 20, $\mathrm{n}^{\circ}$ 1, jan-abr. 2018. Disponível em: https://seer.ufs.br/index.php/eptic/article/view/8516/6799. Acesso em 28 jan. 2020.

BOLAÑO, César. Indústria cultural: informação e capitalismo. São Paulo: Hucitec/Polis, 2000.

Edise, 2015 .

. Campo aberto: para a crítica da epistemologia da comunicação. Aracaju:

BONNET, Alberto e PIVA, Adrián. Estado y Capital: El debate alemán sobre la derivación del Estado. Buenos Aires: Ediciones Herramienta, 2017.

DOWNNING, John D.H. The USSR and satellite communications. Space Policy, Vol. I, No. 3, 1985a, pp. 250-262.

. The Intersputnik system and Soviet television. Soviet Studies, Vol.

XXXVII, No. 4, 1985b, pp. 465-483. 
FUSARO, Willian Casagrande. Forjar a revolução: a esfera pública proletária nos cartazes construtivistas de guerra russos (1918-1921) Dissertação (Mestrado em Comunicação) - Universidade Estadual de Londrina, Londrina/PR, 2020.

KLUGE, Alexander e NEGT, Oskar. Public Sphere and Experience: Analysis of the Bourgeois and Proletarian Public Sphere. London: Verso, 2016.

KURZ, Robert. O colapso da modernização: da derrocada do socialismo de caserna à

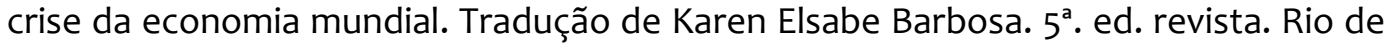
Janeiro: Paz e Terra, 1999.

MARX, Karl. O Capital: crítica da economia política. Livro I: o processo de produção do capital. Tradução de Rubens Enderle. $2^{\text {a }}$. ed. São Paulo: Boitempo, 2017.

ROTH-EY, Kristin. Moscow Prime Time: How the Soviet Union Built the Media Empire that Lost the Cultural Cold War. Ithaca/NY. Cornell University Press, 2011.

. Playing for Cultural Authority: Soviet TV Professionals and the Game Show in the 1950 s and 1960s. In: CROWLEY, David e REID, Susan E (orgs.). Pleasures in Socialism: Leisure and Luxury in the Eastern Bloc. Evanston/IL: Northwestern University Press, 2010.

. Finding a Home for Television in the USSR, 1950-1970. Slavic Review, Vol.

66, No. 2, Verão de 2007, pp. 278-306. Disponível em: http://www.jstor.org/stable/20060221. Acesso em 28 jan. 2020.

. "Loose Girls" on the Loose?: Sex, Propaganda and the 1957 Youth Festival. In: ILIČ, M., REID, S.E., ATTWOOD, L. (orgs.). Women in the Khrushchev Era: Studies in Russian and East European History and Society. Londres: Palgrave Macmillan, 2004.

e ZAKHAROVA, Larissa. Communications and media in the USSR and Eastern Europe. Cahiers du monde russe, Vol. 56, No. 2-3, Abril de 2015, pp. 01-16. Disponível em: http://journals.openedition.org/monderusse/8182. Acesso em 28 jan. 2020.

YWATSUGU, Tatiana Iaquinto. Estúdio Soyuzmultfilm na Guerra Fria: uma análise da animação soviética na era da estagnação. Dissertação (Mestrado em Comunicação) Universidade Estadual de Londrina, Londrina/PR, 2020.

ZAKHAROVA, Larissa. S'habiller à la soviétique: La mode et le Dégel en URSS. Paris: CNRS Éditions, 2011.

. Accéder aux outils de communication en Union soviétique sous Staline. Annales. Histoire, sciences sociales, Vol 68e, No. 2, 2013, pp. 463-497.

. Des techniques authentiquement socialistes? Transferts et circulations dans les télécommunications entre l'URSS et l'Europe (années 1920 - années 1960). Critique internationale, vol. no 66, no. 1, 2015a, pp. 19-35.

. Concevoir l'efficacité des communications en Union soviétique, fin des années 1920-début des années 1930. Histoire \& mesure, vol. xxx, no. 1, 2015b, pp. 69102.

- La reconfiguration des réseaux de communication dans la nouvelle Ukraine d'après-guerre (1944-1952). Cahiers du monde russe, vol. vol. 56, no. 2, 2015, pp. 467-494. 